\title{
НАМЕТКИ К ПЛАНУ РАБОТ ПО ГЕМАТОЛОГИЧЕСКИМ ЧИПАМ С МУЛЬТИПЛЕКСНОЙ МАСС-СПЕКТРОМЕТРИЧЕСКОЙ ЧАСТЬЮ ДЛЯ АНАЛИЗА КРОВИ В РАМКАХ КОСМИЧЕСКОЙ ПРОГРАММЫ
}

Градов О.В.

ИНЭПХФ РАН, Лаб. 007

\begin{tabular}{l}
\hline От: о.v.gradov@gmail.com \\
Дата и время отправки: 20 июл. 2015 г., 03:13 \\
Тема сообщения: \\
\hline Наметки к плану работ по гематологическим чипам для космонавтов \\
\hline Наименование вложения: \\
Наметки к плану работ по крови для космической программы.pdf \\
\hline Ответ: отказ
\end{tabular}

Полный текст документа (без иллюстраций)

Исходя из расширенного анализа литературы, составил план-конспект:

1) Прежде всего, чипы должны обеспечивать возможность работы в двух режимах - с обратимой дегидратацией (после высушивания, после доставки на землю - впрыск реагента через отдельный канал) и с длительным подержанием гематокрита крови / целлокрита, т.е. с сохранением состояния форменных элементов, так как протеомы свежевзятой, консервированной, неконсервированной крови качественно различны (соответственно, нужно обеспечить возможность впрыска гепарина, растворителей, разжижителей среды, детергентов и небелковых, т.е. не мешающих анализу, либо являющихся индикаторами состояния, консервантов).

2) Во-вторых, чипы должны быть центрифугируемыми как вкладыши гематокритной центрифуги и иметь возможность быть использованными в вертикальной фиксации как СОЭ-метры (измерители скорости оседания эритроцитов). Это необходимо для контроля крови как микрогетерогенной среды. Попытки рассматривать кровь чисто как гомогенную среду, характеризуемую одним только масс-спектрометрическим методом, обречены на провал, так как она - ненютоновская жидкость с изменением локальной концентрации, эффективности экстрагирования и электрофореза (значит 
и выделения с использованием PaperSpray) в зависимости от состояния / реологии. Нужно обязательно характеризовать образец по другим переменным, определяя его «анализопригодность в масс-спектрометрии» по отношению объема эритроцитов к объёму жидкой части крови, соотношению фракций белков плазмы, способности к гемокоагуляции / плазменному (вторичному) гемостазу.

3) В случае крови как совокупности разных типов клеток - форменных элементов, их разнообразие при аддитивном MS-анализе с использованием ESI-подобных техник неизбежно будет являться источником артефактов и ложноотрицательных выводов (в силу размывания химизма по выборке клеток). Протеом крови без учета клеток средняя температура по больнице. Соответственно, как минимум, нужно обладать методами быстрого морфологического тестирования с использованием программы для распознавания образов с обучением на эталонных препаратах; как максимум нужно проектировать чип сразу как клеточный сортер, т.е. заменитель проточного цитометра, широко используемого в зарубежной гематологической клинической и лабораторной практике. Технологии для этого у нас есть, так как выполненный на базе известного Вам завода образец чипа по топологии исходно разрабатывался для разделения клеток и микрочастиц (сортер на чипе). Программа для автоматизации распознавания образов клеток, обучаемая по эталонной выборке, была разработана А.В. Нотченко в 2012 году (см. нашу статью по лабораториям на чипе в «Журнале радиоэлектроники», 2 - 2012 [http://jre.cplire.ru/mac/feb12/5/text.pdf]).

4) В случае изучения крови на предмет содержания гемоглобина и пр., в особенности - в целях предупреждения анемий и функциональных биохимических сдвигов (что, в частности, было описано в экспериментальных полетах в 70-х гг.), целесообразно контролировать оптическую плотность на нескольких характеристических длинах волн (гемоглобинометрия с использованием элементарно вводимых в чип агентов и смежные методы). Помимо стандартного решения - подключения оптоволоконного световода с выводом на полихроматор (например - компактный спектрофотометр «Ocean Optics»), есть возможность простого и компактного решения на чипе. Если вместо матриц Байера поставить матрицы фильтров на соответствующий максимум - можно в форме фотометрии на КМОП-чипе производить гемоглобинометрию. На той же платформе с выводом на микросхему АЦП можно осуществлять в режиме реального времени электрохимические методы контроля крови (12 вариантов). 
5) При изготовлении части стенок и канавок чипа из ионоселективного материала (я уже нашел потенциального изготовителя в РФ) или использовании структур ISFET (ионоселективных полевых транзисторов) можно при разделении плазмы крови от форменных элементов проводить измерение содержащихся неорганических ионов, не просто осуществляя тем самым анализ металломики и элементомики аналита, но и производя диагностику микроэлементозов и дефицитных состояний. Для космоса это - самое оно, так как, в частности, у космонавтов вымывается кальций, зачастую необратимо сдвигается ионный обмен, нарушается элементный статус и т.д. Нашел специалистов, которые готовы производить анализ по неорганическим элементам с ними, получая данные по протеому масс-спектрометрически, можно будет весьма качественно характеризовать бионеорганическую химию тела человека при полете, а в качестве экспресс-тестов внедрить откалиброванные ими элементометрические гематологические лаборатории на чипе.

6) Так как морфология клеток в невесомости стремится к форме протопласта - сфере / телу вращения, но различным патологическим состояниям соответствуют различия в форме клеток (эллиптоцитоз, эхиноцитоз, стоматоцитоз и пр.), что, в частности, имеет место при железодефицитных состояниях / анемиях, для диагностики нужна модель поведения таких форм клеток в невесомости. Кроме того, показатели СОЭ в отсутствие земной гравитации нерелевантны, показатели гематокрита отчасти тоже нерепрезентативны после возвращения из микрогравитации в поле тяготения (если судить исходя из данных малочисленных работ). Стандартный подход не подходит - нужно доводить численные модели, используя труд сотрудников ИМПБ, ИТЭБ и др. В противном случае, будет недостаточно качественное разделение на фракции, с которых будет производиться эджекция вместо аддитивного PaperSpray-я.

7) Я вижу формат работы чипа следующим образом. С одного из концов чипа стилетигла, с помощью которой осуществляется прокол и забор крови. После забора идет стадия подачи через вентиль с перекрытием для соблюдения стерильности. Затем, в соответствии со схемой известного чипа-прототипа, происходит разделение клеток по канавкам. После того, как в каждой канавке накапливается достаточно аналита прибор готов к вставке в приемный модуль головы масс-спектрометра. Далее (как в известных чипах для Agilent 1260 Infinity HPLC-Chip-MS system, объединяющих в HPLC-Chip II колонку разделения и компоненты наноэлектроспрея), разделенный в 
теле чипа (сортере вместо хроматографической колонки) аналит подается с разных точек (видимых на схеме как круглые оконечные головки) на спрей с параллельной подачей жидкости, обеспечивающей смытие клеток в электрораспыляемую каплю. За счет наличия более сильного, чем есть у нас сейчас, микроскопа на ESI-голове можно контролировать и регулировать подачу, строя векторные поля PIV / LDV.

8) Список приборов для проекта: перистальтические насосы программируемые 2 шт., пневматический микроинъектор + микроманипулятор пневматический (в наименее благоприятном случае - механический). Все остальное я попытаюсь достать сам - в случае, если проект благожелательно пройдет экспертизу.

9) Интересные ответвления проекта, которые могут возникнуть. Дегидратация многих биожидкостей в контролируемых условиях имеет существенное диагностическое и научное значение. Существуют специальные упрощенные чипы для этого. Введены (не нами, также, как и упрощенные чипы) термины «тезиограммы дегидратации», «кристалломика» и пр., которые говорят о диагностической ценности дегидратации в контролируемых условиях. Однако достижение таких условий достаточно тяжело достижимо вне единого неупрощенного термостатируемого чипа. Если произвести масс-спектрометрический анализ крови при дегидратации в «хороших» и «плохих» условиях, то результаты будут качественно различными, так как разные популяции клеток уйдут в разные «фазы» или сегментированные фации капли. Поэтому, если в перспективе планируется использование не только прямой биохимии, морфомики и электрофизики, но и форм дегидратации как диагностических дескрипторов или предикторов, то нужно будет изучить формы дегидратации в чипе, оптимизировать топологию для реализации идеологии неразрушающего контроля (без артефактов в результате разрушения неправильным хранением, неправильной дегидратацией) и, в перспективе, апробировать в условиях микрогравитации. Яхно с соавторами уже немало времени продвигает автоволновую модель дегидратации капель, в ЦФ РАН рассматривают термо-, фото- и СВЧ- индуцированные технологии дегидратации. В связи с этим, возможно, удастся найти неразрушающий, но эффективный индуктор дегидратации крови - например NIR, при котором препарат в чипе будет сохранен в сравнительно достоверном состоянии. Есть ряд наблюдений по изменению этого процесса в разных атмосферах и климатических условиях. Сейчас у нас в комнате есть климатическая газонаполнимая камера, взятая для этих целей. Изучение этого 
даст возможность говорить о применимости атмосферного / газо-атмосферного ESI и MALDI (последний с высушиванием прямо на подложке-матрице) для измерения достоверных концентраций реальных белков. Я уже нашел биологов, которые нам готовы безвозмездно в этом помочь (только за соавторство в статье). Соединением морфомики морфологии биологических жидкостей («белковых тел») и протеомики можно достигнуть доселе не применявшейся в космической медицине новизны и полноты морфобиохимического анализа.

Задел в этой области (3 наиболее важные из 10 работ):

1. Notchenko A.V., Gradov O.V. Elementary Morphometric Labs-On-a-Chip Based on Hemocytometric Chambers With Radiofrequency Culture Identification and Relay of Spectrozonal Histochemical Monitoring. Visualization, Image Processing and Computation in Biomedicine. DOI: 10.1615/VisualizImageProcComputatBiomed.2013005968, Vol. 2 (2013)

2. Нотченко А.В., Градов О.В. Элементарные морфометрические лаборатории на чипе на основе гемоцитометрических камер с радиочастотной идентификацией культур и трансляцией спектрозонально-гистохимического мониторинга. Журнал радиоэлектроники, Вып. 2 - 2012, Печатный объём: 27 стр. [URL: http://jre.cplire.ru/jre/feb12/5/text.pdf]

3. Notchenko A.V., Gradov O.V. A Five-Axis Arm-Manipulator Laser System \& an Algorithm for Digital Processing of Output Data for Recording and Morpho-Topological Identification of Cells and Tissue Structures. Visualization, Image Processing and Computation in Biomedicine. DOI: 10.1615/VisualizImageProcComputatBiomed.2013005967, Vol. 2 (2013)

Документ подготовлен к печати: Архив группы биофизического приборостроения 